\title{
Cloud Computing a Solution for Globalization
}

\author{
Prof. Dr Tanvir Ahmed \\ Head of Computer Science and Information Technology Department Lahore Leads University, Lahore \\ Pakistan
}

\begin{abstract}
Security issues and exploded human population in the world have dictated many new trends to defend haves from have-nots and vice versa, like globalization through social media while maintaining the geographical boundaries and concept introduced under WTO (World Trade Organization)- Free trading in the world. We know that Globalization is the most significant part of this century which is based only and only upon developments in Information Technology in form of Networking and Software solutions. As business grows, multiregional offices are needed and they required networked computing and information services. For example In Pakistan, lots of offices of multinational companies are working and they are developing and enhancing their business by full filling the demand and needs of customers of the particular city or country. The demand is increasing manifold with every day passing. So huge computing and storage power is needed everywhere and to everyone at every moment which is beyond the capacity of traditional systems already in vogue. New solutions like Cloud computing seems the solution to address such multi-scaled demands. Education system nowadays is the growing business in Pakistan, in this we paper we studied in detail the Education System of Pakistan, what are the flaws of current system and how a new cloud based E-Learning solution helps to improve this system.
\end{abstract}

Index Terms: Globalization, Cloud Computing, Information Technology.

(C) 2016 Published by MECS Publisher. Selection and/or peer review under responsibility of the Research Association of Modern Education and Computer Science.

\section{Introduction}

Nowadays computer and information technology reach in every part of our society like health, Education, military, private and public sectors; it become the fundamental part for almost all organizations. This technology helps business grows by making communication and instant commerce globally available between different organizations and in the internal organization as well.

The reason behind the increasing expectation for the use of computer and information systems is that society

* Corresponding author.

E-mail address: profcs.1lu@gmail.com 
needs instant communication with instant results and performance from all businesses at all times. To meet such expectation we all know that Cloud Computing developed much more interest in the field of Information Technology. It is based on many old and few new concepts like Virtualization, Service Oriented architectures, distributed and grid computing. The term "Cloud computing" is define as computing place where all kinds of users can temporarily utilize the computing infrastructure over the network supplied as a service by cloud provider in order to fulfil user demands. It involves groups of servers and software networks that give online access to users over computer resources with the centralized data storage.

In this paper, we will explore cloud computing approach towards the rapid computing and IT services, architecture of Cloud computing, architecture wise different Cloud computing based solutions. In Research section we describe the current education system its flaws and how can we improve this system by introducing a web based E-learning system developed using cloud computing approach.

\section{Literature Review}

\section{Cloud Computing:}

The "Cloud computing" is define as the computing place where all kinds of users can temporarily utilize the computing infrastructure over the network supplied as a service by cloud provider in order to fulfill user demands. It involves groups of servers and software networks that give online access to users over computer resources with the centralized data storage.

We are living in the modern age of technology and the cloud computing is a game changer that brought a great revolution in the Information and Technology history. Before moving towards its pros and cons, first we need to understand what's the Cloud Computing and how it leverages the enterprise businesses and how it bring change and ease in the life of end user. The concept of Cloud Computing is come with the utilization of resources and to provide set of data services to the businesses and as well as end users. The Cloud Computing provides Compute, Network and Storage as a service to the consumers. The Cloud Computing comes with the concept of "ready to go" it means that it provides readymade services to the end users. The end user has to pay some money against his usage that we can express in a single sentence "Pay as you go". Today the world has become a global village whereby enterprise corporate are being expanded beyond the geographical boundaries where they need to keep the administration and management system centralized to control their branches from one single command and control center. The Cloud Computing makes it possible for the enterprise corporate to scale out beyond and to communicate with the other organizations beyond the geographical limits. The Cloud Computing helps out and facilitate in every sector of life it could be government or private and it improves the productivity and creativity. In the age of information and technology the computer is accessible to everyone.

\section{History of Cloud Computing:}

As we all know questions are always arising whenever there is an introduction of new technology and the question are like "when was it invented?", "When it was first mentioned?" and what are the prospects for its future?". Cloud computing is introduce in $21^{\text {st }}$ century but this is not true as Cloud concepts was present in past in different shapes. Here, let us take you back to that time.

\section{Evolution started in 1950s with mainframe computing.}

In past, there is a central mainframe computer whose access was provided to multiple users. Because of the costs of main frame computer was very high that organization unable to buy mainframe for every employee also it is not possible that an individual person will use a large capacity of storage, so the person having mainframe will provide shared access to different resources through dumb terminals. That was the first time where resource sharing concept was introduced. 


\section{In 1970, the concept of virtual machines (VMs) was created.}

In this concept the idea is to create virtualization software that can run one or more operating systems at a time and these (virtual) operating systems are using one physical hardware machine. These VM operating systems took the shared access \& resource sharing concept to the next level, which allows multiple distinct computing environments available on one physical environment. Virtualization drives the technology, and was an important factor in the idea development of virtual networks.

\section{In the 1990s, telecommunications companies started offering virtualized private network connections.}

Historically, telecommunication companies initially offered dedicated single point-to point data connections. Later same service was offered by virtualized private networks connections, this offer of VPN connections reduced the cost in a sense that instead of creating new physical infrastructure for more connections the telecommunication companies provide users shared access on the existing physical infrastructure.

\section{Architecture of Cloud Computing}

Cloud computing has three types of models which are as follows:

- Infrastructure as a Service (IaaS)

- Platform as a Service (PaaS)

- Software as a Service $(\mathrm{SaaS})$

\section{Infrastructure as a Service (IaaS):}

In this model, users can use certain components of IT infrastructure provider, the users don't have a control on the entire cloud infrastructure but they do have control over selection potions such as firewall, operating system, storage and deployed applications.

\section{Platform as a Service (PaaS):}

In this model, a number of applications which forms a platform is subscribed as a service by users. For example, a software tools may be used as a programming and software platform.

\section{Software as a Service (SaaS):}

In this model a single application provides services to users and acts like a service. Such services are often accessed via Web browser.

\section{Private Cloud:}

Private Cloud is used by some particular organization. In this case a particular computing infrastructure is owned by the organization and the employee of the particular organization access the computing and other resources of the cloud through VPN.

\section{Public Cloud:}


A public cloud is based on standard computing model in which service provider makes resources, like applications and storage available to general public over the internet. Public cloud services mostly offered on a pay-per-usage model.

\section{Hybrid Cloud:}

It is a mixture or both public and private cloud and utilizing both public and private cloud services in order to perform different functions within the organization.

\section{Management Process for an it Based Solution:}

In general, when you are going to start a new branch office, you will require elements like data centre, network and infrastructure, telecommunication systems, web servers, database server, backup servers and storage and client computers, and all these require high information security. It doesn't matter how all of these will be implemented, but some general steps of project management must be taken in order to assess exactly what IT infrastructure and systems are needed for the business expansion and how to implement it. We require a chief technical architect who will work with the business representatives and list down what will be needed for all the daily operations of the new office. For example how many systems require for an ERP and email services, this is done in the project conception stage. During this phase, project shows all the technical stuff that is needed to run business operations.

The next phase is project planning, in this phase we determine working activities, required resources, cost estimate, budgeting, Risk management plans, quality standards, and after analyzing and studying each and every thing a final plan will be made.

The last phase is Project Execution where the work on the final plan started this includes project team development, receiving proposals against requests, selection of vendor on the basis proposal best suits for a company, execution of the work packages and performs quality assurance procedure and in the end delivers project information and control to the concern persons.

These three phases of project management is applicable when IT solution is based on Cloud computing to meet business need of a company having branch offices in different regions.

\section{Cloud Computing Solutions}

In this article we are taking Software Company who wants to starts it's off shore office in Pakistan and we suggest different Cloud computing based solutions in order to build the setup of off shore office.

\section{Private Cloud based Solution:}

The organization which having well establish IT infrastructure and having IT as their core business is always following private cloud based solution. This solution usually a better choice to provide IT services to new branch office. In such case, servers, data centres and all other devices are behind firewall of the company's network present in the head office. 


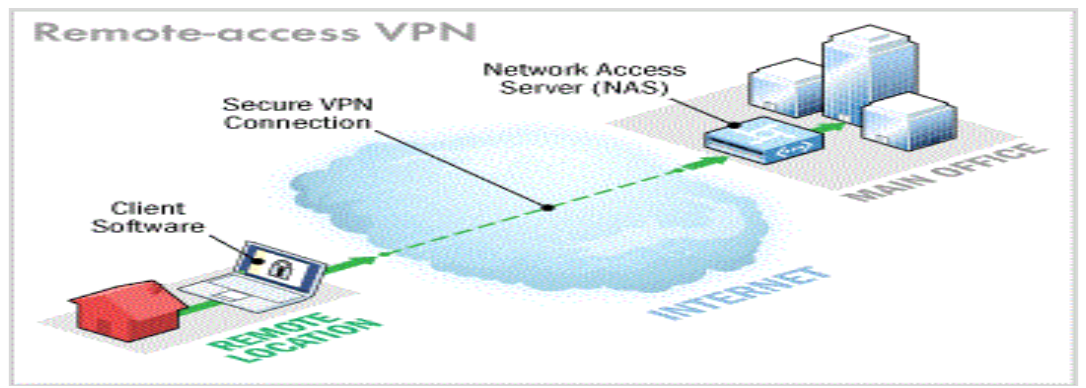

Fig.1. Architecture of Private Cloud based Solution.

While the other offices access company's network through VPN or web browsers. In private cloud all components and IT infrastructure is under control by the organization.

\section{Federated Cloud based Solution:}

Federated cloud is same as private cloud but the only difference is that equipment and servers are distributed among head office and branch offices. This is only necessary when different branches have different goals and each providing different IT services. For example, one branch only works in storage and the other provides Operating System Services like security patch updates and resolving other OS related problems. The architecture of this type of cloud based solution is shown in figure2.

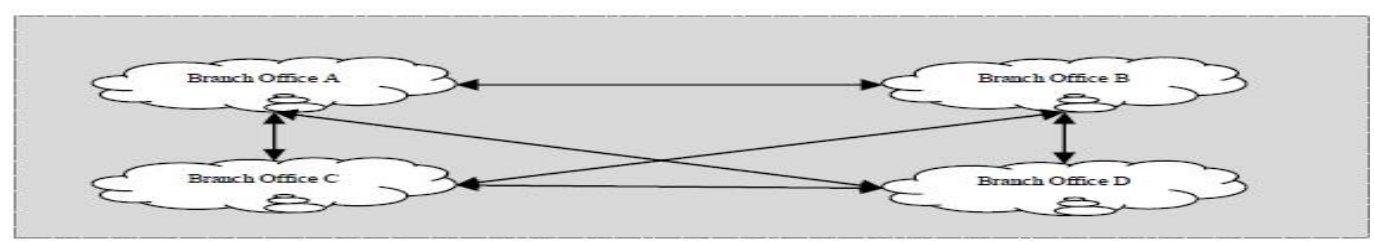

Fig.2. Architecture of Federated cloud Based Solution

\section{Public Cloud based Solution:}

A public cloud based solution is useful for those organizations whose subscriber needs computing and services from providers present in public cloud, and these organizations have no plan or interest to build their own infrastructure, as shown in fig 3. Also the subscribers of this solution are normally running applications which requires large amount of data storage and computing.

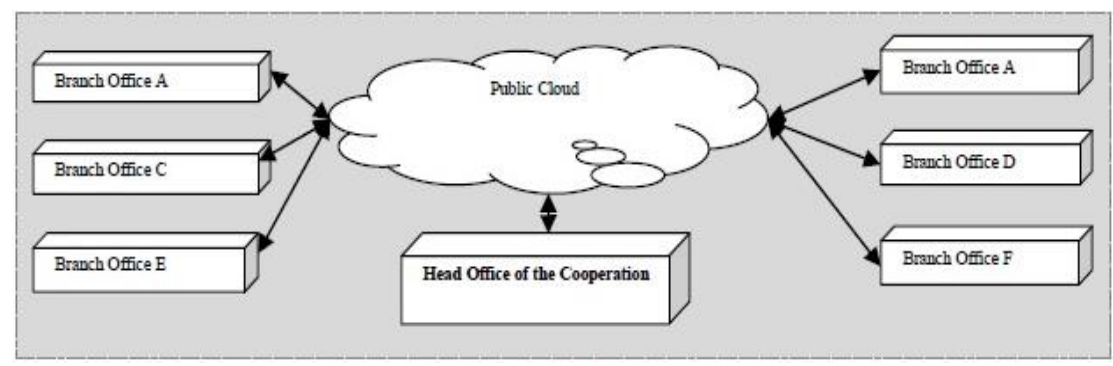

Fig.3. Architecture of Public cloud Based Solution 


\section{Hybrid Cloud based Solution:}

As we all know that hybrid cloud is the mixture of both public and private cloud and the solution will be applied for those organization that has sufficient IT infrastructure to fulfil their current business needs, but in case if the expansion of the current infrastructure required then instead of investing money on the expansion they chooses public cloud computing services for the new business. Fig 4 exhibits such arrangement.

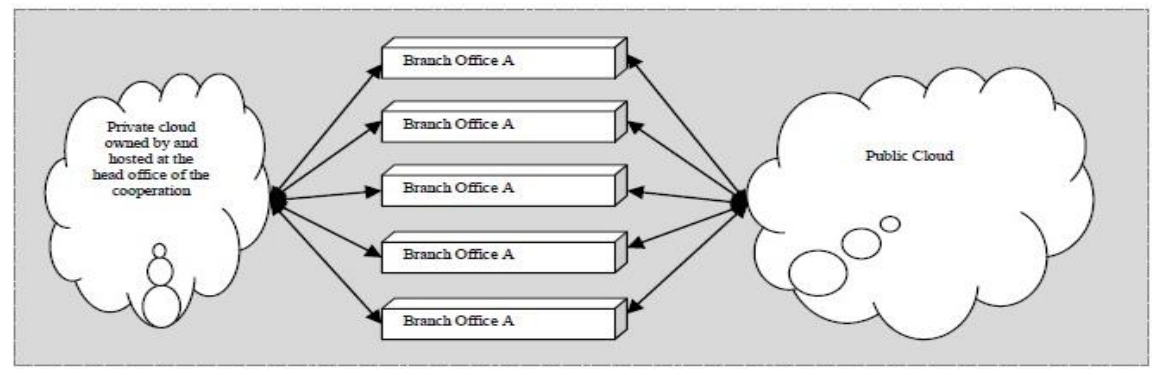

Fig.4. Architecture of Hybrid cloud Based Solution

\section{Research Data}

Here in this research after thorough study of the Education System in Pakistan, we recommend few cloud based systems for students of every level. These systems are discussed below:

The present system of education in Pakistan is a legacy of colonial British rule of sub-content which was designed to keep the local public out of race in managing the ruling affairs. But remain submissive, ignorant and contributively towards prolonging their rule. The end products of this system are prepared for low paid clerical jobs. Nobody has ever thought to review the prevailing system for modifying and updating since last 65 years of independence. The system needs complete overhaul, set new emphasis areas as per national priorities, needs and potential resources, aligned with technological advancements and focus on turning into skilful nation. Our end product has to be worthy of dignified independent nation. The system should have been demand oriented instead of supply oriented. Drastic changes are to be inculcated where true Muslim from Pakistan is prepared who is skilful, have no language barrier and religiously conscience dutiful end-product.

- Compose Text Books: Devise new Text Books through one time effort of digitizing curricula and linking related known facts and materials in form of audio, video, simulations and software utilities hence nullifying the need of heavy bags. Introduction of computers for a virtual classroom; a paperless yet interactive class room environment, where students log in to their respective class accounts and their daily progress is measured and evaluated will be the salient most teaching and learning device. This facility will revolutionize the teacher's efforts towards invigilation and monitoring the students' progress. A lesson not attended is not lost but rather it is still available. This concept transcends the traditional blackboard scuffle where not all students have equal access to visual benefit of class work

- Digitize the Contents: The modern approaches of teaching and learning should be launched to cater the needs of expanding economy of the country. Purpose built tutorials be developed to overcome the deficiencies resulted due to lack of qualitative teachers. Text books be digitized and linked completely with reference materials in form of video, audio, text notes, graphical models, simulations, and software utilities. Such well-defined tutorials can replace good instructors. The present system of education is producing clerical stuff whereas the nation needs skilled manpower adorned with technological knowledge in modern sciences. Even in the age of information, same old methods are put into. As with IT and internet have manifold better material available on computers for doing repetitive type of jobs to 
make the students understand the digitized conceptual models audio, video clips. Taking a leaf from the ongoing social networking sites which are detriment to our children's time, we can establish a communal social networking study group mechanism where students interact for betterment and pursuit of knowledge.

- Introduce E-Learning Solution: E-learning can produce great results by decreasing costs and improving performance. Unlike one-time classroom session, the e-learning course is available for others. This includes the static e-learning course as well as any ongoing conversations in networked communities. One of the challenges with making e-learning effective is how to manage the courses and access the resources. Freeing up the course navigation and giving the learner more control would be the transformed education process in information age. Do people have access to the resources when the course is complete? Can they retake it? Are you punishing them for failing? E-learning is cost effective and can produce great results. It's all a matter of how you use it. It is pity that e-learning is considered as the one of the tool to be used in existing education process based upon printed media of books and libraries where physical interactions of students is mandatory to fetch desired knowledge.

- The concept of E-libraries and the linkage with the curriculum through computers is a new paradigm of learning is given in figure 5. If you're using a learning management system you might consider how those impacts the learning and it look like model shown below:-

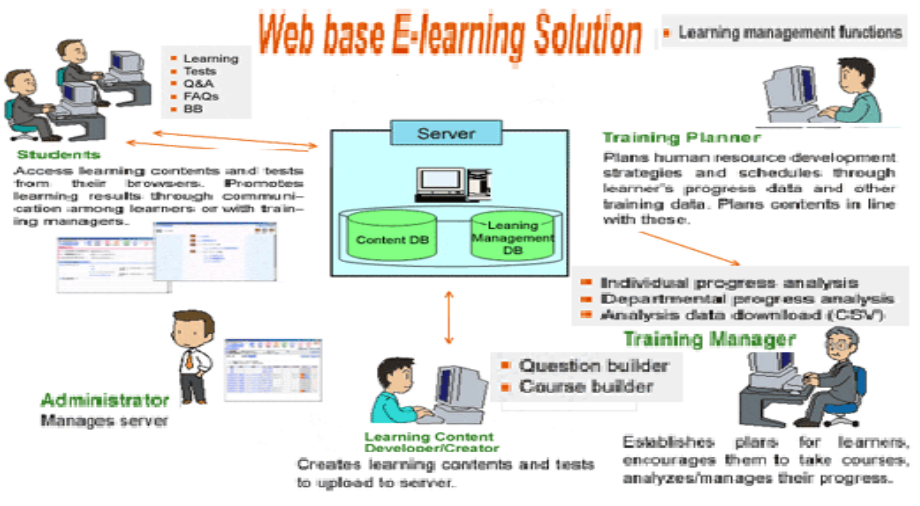

Fig.5. Web Based Solution

If implemented efficiently and linkage of library data in form of Text, Audio/ Video Clips, Simulations, Illustrations (graphically, statistically), conceptual models of the knowledge pieces is managed for curriculum courses then the concept of e-learning get realized. Understanding e-learning's value helps you make the best decisions about when and why to use it. E-learning has definite benefits over traditional classroom training. While the most obvious are the flexibility and the cost savings from not having to travel or spend excess time away from work, there are also others that might not be so obvious but critics are apprehensive due to its potential disadvantages (i.e. boring text-based courses, technophobia, loneliness) which can easily be alleviated with a properly designed courses and enriched fully with linkage of E-library materials.

\section{Role of Instructors be redefined:}

Teachers' role in schools will be reduced as coordinators while centrally subject specialists will continue further improvement of digital tutorials and contents. So Mafia will be curtailed and tuition system will be winded up with computer based access of curriculum material on Internet round the clock. Moreover, whatever 
the role remain the training to the teachers be so rigorous that all come to the same standard of instructional excellence. A standard of teachers be maintained to restrict poor quality teachers to continue. To attract potentially high candidates in teaching profession, their pays be enhanced and promotion structure defined. It should be made very clear at all levels that the foundation of a nation laid by competent, selfless and committed teachers is the only way forward to match the world. With introduction of e-learning the teachers have to follow technological solution of information dissemination. He will not be bothered to plan lectures, conduct exams and tests, mark papers and prepare results. Everything should be through computers. Those who become subject specialists and curriculum qualified through national teachers' standard accreditation council would be employed in software houses where the tutorials are being modified to strengthen the contents for more affectivity. Similarly class coordinators would assist students to get connected with related tutorials or testing system.

\section{Cloud based Solution for E-Learning Software Development Portal}

After studying all four Cloud based solutions and the system having sections like Digitize Textbooks, Tutorials, Virtual Class Room, E-Libraries and other software utilities for enhancing the skills and capability of students required a large storage and huge computing. We think that Hybrid Cloud based solution will suit for the development of such Educational Solution, The reason behind choosing this type of solution is that Hybrid Cloud based solution is the mixture of both private and public cloud based solution and by using this cloud based solution privacy of students and teachers will be maintain, each student can have a separate user account where he/she will come to know his/her progress, attend classes, attempt quizzes and can submit their assignments. Due to public based all the books, tutorials, digitize textbooks and audio, video lectures are publicly available for all where student of every level can able to access it.

The advantage of using Hybrid cloud based solution is that Sys Admin services is no more required to take backup of data after every week also no need to update security and other patches of operating system. As this all will be handling by Cloud providers.

\section{Conclusions}

Due to the advancement in computer and network technologies, more reliable and powerful computing and IT services are now available over internet. High speed internet services make it possible for many users to use the Cloud computing services instead of investing money on building their own IT infrastructure. This Cloud Computing services brings both opportunities and challenges. In this paper, we illustrated Cloud computing, it's services (IaaS, PaaS, SaaS) and different kinds Cloud Computing Environments. Then we presented Architecture of different Cloud based solutions: Private Cloud Solution, Federated Cloud Solution, Public Cloud Solution and Hybrid Cloud Solution. In these solutions we discussed how these cloud based solution are beneficial for education businesses expanded in multi regions.

In the end we discussed the education system in Pakistan, its limitation and flaws and how can we improve this system by introducing a web based system which can provide facilities to students like virtual class room, digitizing textbooks, audio, video lectures, educational based tutorials and how we shall improve the skill and capabilities of teachers and in the end how these solution will become beneficial for students in future.

\section{References}

[1] Buyya, R., Yeo, C. S. and Venugopal S. (2008) Market-Oriented Cloud Computing: Vision, Hype, and Reality for Delivering IT Services as Computing Utilities. Department of Computer Science and Software Engineering, The University of Melbourne, Australia. pp. 9.

[2] Buyya, R., Ranjan, R. and Calheiros, R.N. (2009) Modeling and simulation of scalable Cloud computing 
environments and the CloudSim toolkit: Challenges and opportunities, International Conference on High Performance Computing \& Simulation, HPCS '09. Page(s):1 - 11.

[3] Brandic, I. (2009) Towards Self-Manageable Cloud Services, Annual IEEE International Computer Software and Applications Conference, 2009. COMPSAC '09. 33rd Volume 2, Page(s):128 - 133

[4] Cohen, D., Lindvall, M. and Costa, P. (2004) An introduction to agile methods, Advances in Computers, New York, Elsevier Science, pp. 1-66.

[5] Dikaiakos, M.D., Katsaros, D., Mehra, P. Pallis, G. and Vakali, A. (2009) Cloud Computing: Distributed Internet Computing for IT and Scientific Research, Internet Computing, Issue 5, Volume 13, IEEE.

[6] Gruman, G. (2008) What cloud computing really means. InfoWorld (http://www.infoworld.com), retrieved 2010-01-17 from http://www.infoworld.com/d/cloud-computing/what-cloud-computing-really-means-031.

[7] Fouquet, M. and Niedermayer H., Carle G. (2009) Cloud computing for the masses, in Proceedings of the 1st ACM workshop on User- provided networking: challenges and opportunities, pages 31-36.

[8] Kandukuri, B.R., Paturi, V.R. and Rakshit, A. (2009) Cloud Security Issues, IEEE International Conference on Services Computing, SCC '09. Page(s):517 - 520.

[9] Kaufman, L.M. (2009) Data Security in the World of Cloud Computing, Security \& Privacy, IEEE, Volume 7, Issue 4, Page(s):61 - 64.

[10] Li, X., Li Y., Liu T., Qiu J. and Wang F. (2009) The Method and Tool of Cost Analysis for Cloud Computing, IEEE International Conference on Cloud Computing, CLOUD '09. Page(s):93 - 100.

[11] Pearson, S. (2009) Taking account of privacy when designing cloud computing services, Proceedings of the 2009 ICSE Workshop on Software Engineering Challenges of Cloud Computing, p.44-52.

[12] Project Management Institute (2004) Guide to the Project Management Body of Knowledge, 3rd Edition.

[13] Stantchev, V. (2009) Performance Evaluation of Cloud Computing Offerings, Third International Conference on Advanced Engineering Computing and Applications in Sciences, ADVCOMP '09, Page(s): $187-192$.

[14] Harris Wang, V. (2011) Cloud Computing based IT solutions for organization with Multiregional Branch Offices. School of Computing and Information Systems, Athabasca University, Canada. Van der Geer J.

[15] Hanraads JAJ, Lupton RA. The art of writing a scientific article. J Sci Commun 2000; 163:51-9.

\section{Authors' Profiles}

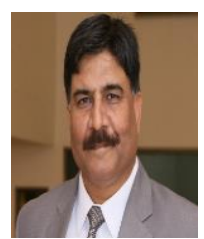

Dr. Tanvir Ahmed is equipped with sound academics, multifaceted enriched experience, varied dimensional competencies and armory of skills. His personal and professional growth is systematic, methodological, progressive and institutionalized. The foundation of his development as a technical resource rests upon his graduate degree of Aeronautical Engineering (BE Avionics) which was further strengthened with post graduate diplomas, professional courses and a doctorate degree in Computer Sciences from the UK with specialization in Software Engineering. He also underwent six months specialist training in China to gain expertise in computer-based projects development and management. He served with candid grip on professional matters in different capacities and institutions and remained deeply involved in Computer education, computer based activities and projects. He is an experienced professional with almost 40 years of continued work in the field under the most demanding, stressful and difficult operational and environmental conditions. He is working in corporate sector Universities as Professor, HOD and Dean before joining Lahore Leads University as Professor in Computer Science Department.

How to cite this paper: Tanvir Ahmed,"Cloud Computing a Solution for Globalization", International Journal of Education and Management Engineering(IJEME), Vol.6, No.4, pp.30-38, 2016.DOI: 10.5815/ijeme.2016.04.04 